\title{
TRADUÇÃO COMO (RE)CONHECIMENTO: LIÇÕES DE TROTULA PARA A HISTÓRIA DAS MULHERES E DA MEDICINA*
}

\author{
TRANSLATION AS (AC)KNOWLEDGE(MENT): TROTULA'S \\ LESSONS FOR THE HISTORY OF WOMEN AND MEDICINE
}

\begin{abstract}
Karine SIMONI**
Resumo: O percurso que assinala a evolução do saber médico e botânico se entrelaça, de modo imprescindível, com a história da cultura das mulheres. De fato, desde os tempos mais remotos, as funções da mulher, voltadas predominantemente à gestão da dimensão interna da casa e ao domínio do espaço fechado, deram-lhe o domínio da esfera da geração da vida, da fertilidade e do mundo natural, dentro do qual se fazia portadora do conhecimento e dos segredos da cura (MADERNA, 2017, p. 09). Dentre os nomes que se destacam na história das mulheres e da medicina, Trotula de Ruggiero - que, no século XI, desempenhou suas atividades de médica e professora na Escola de Medicina de Salerno, sul da Itália, e que teve a sua presença histórica negada por longo período - parece alcançar cada vez mais notoriedade nos séculos XX e XXI, a considerar estudos e traduções advindos de diferentes partes do mundo e em diferentes línguas. $O$ presente estudo pretende evidenciar como a tradução é uma importante ferramenta e meio para o (re)conhecimento da obra de mulheres como Trotula. Será realizada uma reflexão a partir do tratado De passionibus mulierus [Sobre as doenças das mulheres], escrito por Trotula, no qual trata de elementos que permeiam a saúde, a doença e a beleza das mulheres, visando analisar em que medida a cura pelas plantas, os preceitos de Hipócrates e Galeno, a defesa da higiene e da boa alimentação e o cuidado do organismo em sua relação com o social podem se constituir em lições de Trotula para as mulheres do seu e do nosso tempo.
\end{abstract}

Palavras-chave: Trotula di Ruggiero. Tradução. História das mulheres. História da Medicina. Lições.

Abstract: The path that marks the evolution of medical and botanical knowledge is intertwined with the history of women's culture. Since the most remote times, the functions of women, predominantly focused on the management of the internal dimension of the home and the domain of the enclosed space, have given them the domain of the generation of life, fertility and the natural world, within which they became bearer of the knowledge and secrets of healing. Among the names that stand out in the history of women and medicine, Trotula de Ruggiero - who performed her activities as a doctor and teacher at the School of Medicine in Salerno, southern Italy, in the 11th century, and whose historical presence was denied by long period - seems to reach more and more notoriety in the $20^{\text {th }}$ and $21^{\text {st }}$ centuries, if studies and translations from different parts of the world and in different languages are considered. This paper aims to show how translation is an important tool and means for the (ac)knowledge(ment) of the work of women like Trotula. A reflection will be made based on the treatise De passionibus mulierus [On women's diseases], written by Trotula, in which she deals with aspects of women's health, disease and beauty, aiming to analyze the extent to which plant healing, the precepts of Hippocrates and Galen, the defense of hygiene and good nutrition, and the care of the organism in its relationship with the social can constitute Trotula lessons for the women of her and our time.

Keywords: Trotula di Ruggiero. Translation. History of women. History of Medicine. Lessons.

\footnotetext{
* Este estudo foi feito como parte das atividades realizadas no âmbito de pós-doutoramento no Programa de PósGraduação em Ciência da Literatura da Universidade Federal do Rio de Janeiro.

** Doutora em Teoria Literária pela Universidade Federal de Santa Catarina (UFSC) e Pós-Doutora em Estudos da Tradução pela mesma instituição; professora da UFSC. E-mail: kasimoni@gmail.com. ORCID: https://orcid.org/0000-0003-4965-7196.
} 
Em Medichesse. La vocazione femminile alla cura [Médicas ${ }^{1}$. A vocação feminina para a cura], publicado em 2017, a autora, Erika Maderna, enfatiza que o percurso que assinala a evolução do saber médico e botânico se entrelaça, de modo imprescindível, com a história da cultura das mulheres. De fato, segundo a autora, desde os tempos mais remotos, as funções da mulher, voltadas predominantemente à gestão da dimensão interna da casa e ao domínio do espaço fechado - em que predominava "a observação, o respeito, a humildade, a prática empírica, onde se operava uma forte distinção em relação à abordagem tipicamente masculina de domínio e controle dos elementos" ${ }^{\text {2 }}$ (p. 09) -, deram-lhe o domínio da esfera da geração da vida, da fertilidade e do mundo natural, dentro do qual se fazia portadora do conhecimento e dos segredos da cura. Dito de outro modo, se os homens haviam dominado o universo da palavra e da escrita, as mulheres realizavam sua autoridade no mundo natural, e essa ordem inerente que diferenciava as competências respectivas a cada sexo e que colocava o saber feminino no campo do cuidado do corpo adoecido teria sido, por muito tempo, aceita e respeitada pelos homens (MADERNA, 2017, p. 09).

Tal maneira de perceber os espaços e saberes teria prevalecido, pelo menos, ainda segundo Erika Maderna, até o século XII, quando a normativa que regia as práticas médicas foi submetida a uma regulamentação mais rígida, fato este que assinalou a passagem da simples prática para a regulamentação da profissão, marcando, assim, uma mudança substancial para a história da medicina e para a história das mulheres (MADERNA, 2017, p. 54). Um dos grandes responsáveis por essa mudança foi o imperador Federico II (1194-1250), que, em 1231, tornou obrigatória para o exercício das práticas médicas a frequência na Escola de Medicina de Salerno, o mais prestigioso centro de estudos teórico-práticos da península itálica, reconhecido também em toda a Europa (MADERNA, 2017, p. 55). Sem dúvida, contribuíram para o reconhecimento da Escola de Medicina de Salerno como centro de excelência o fato de a cidade se localizar em uma posição geográfica favorável, no sul da Itália, banhada pelo mar Tirreno e rodeada de montes e da planície de Sele, o que facilitava a agricultura e a circulação de pessoas, mercadorias e ideias, inclusive do conhecimento médico advindo de especialistas gregos,

\footnotetext{
${ }^{1}$ Traduzo "medichessa" por "médica", mas chamo atenção para o seguinte contexto cultural: tanto "medica" como "medichessa" são usados em italiano, mas, segundo a Accademia della Crusca, medichessa conserva uma conotação ligada às práticas e figuras próprias da arte médica do passado, mas que hoje estão à margem ou ausentes, como as sacerdotisas curadoras, personagens dotadas de poderes mágicos e de capacidades divinas. Cf. https://www.linkiesta.it/2017/02/la-crusca-si-puo-dire-anche-medica-e-medichessa/. Acesso em 24 mai. 2020.

${ }^{2}$ No original: "l'osservazione, il rispetto, l'umiltà, la pratica empirica, e dove si operava un forte distinguo rispetto all'approccio tipicamente maschile di domínio e controllo degli elementi." Todas as traduções, quando não indicado o contrário, são de minha autoria.
} 
hebreus e árabes. Porém, a maior "novidade" devia-se, sobretudo, à visão laica, quase préhumanística, de governantes como Federico II, que não hesitaram em abrir espaço para que as mulheres exercessem suas práticas médicas não como simples medichesse, mas como mediche formadas através dos livros e das aulas na Escola de Salerno nas mesmas condições que os homens, fato provavelmente inédito até então, e que não se veria mais em boa parte dos séculos seguintes $^{3}$. Desse modo,

A observação livre e laica, irrepetível e peculiar da experiência de Salerno, que
colocava a escola fora do controle direto da Igreja, talvez esteja na base dessa
extraordinária abertura ao mundo das mulheres, aceitas tanto como estudantes quanto
como professoras em todas as áreas especializadas, e não apenas na obstetrícia. [...]
Esse aspecto é de fundamental importância, pois permitiu que as medichesse se
redimissem da condição submersa das praticantes empíricas para se expressarem em
uma dimensão intelectual, teórica, até então controlada pelo mundo profissional
masculino. (MADERNA, 2017, p. 55, tradução minha) ${ }^{4}$.

A principal representante das mulieres salernitanae foi, como se sabe, Trotula di Ruggiero, ou Trotula di Salerno, símbolo das mulheres que conquistaram o reconhecimento médico, inclusive dos indivíduos homens. Como mostrarei a seguir, a existência de Trotula pode ser colocada, pelo menos, um século antes das medidas adotadas por Federico II, e, embora seja difícil precisar as datas da existência de Trotula, inegável é a sua contribuição tanto para a história de Salerno como para a história das mulheres e da medicina. Trotula é, portanto, o foco deste estudo que, na perspectiva da multidimensionalidade proposta por este $\mathrm{V}$ Seminário de Estudos Medievais da Paraíba, almeja refletir sobre dois prismas intimamente ligados: Trotula e Tradução, a saber, pensar a tradução como um ato antes de tudo ideológico e político de mediação intercultural - como, a partir dos anos 80 do século XX, passaram a enfatizar os estudos de Lawrence Venuti (1986, 2002) Luise von Flotow (1997), Barbara Godard (1990) Maria Tymoczko \& Edwin Gentzler (2002), para citar alguns nomes. Dentre as questões levantadas por tais autores/as, está a preocupação em perceber os mecanismos que direcionam as escolhas editoriais e de tradução propriamente ditas. Que interesses regem as

\footnotetext{
${ }^{3}$ Vale lembrar que o imperador Romano-Germânico Federico II é conhecido, grosso modo, pela sua oposição ao poder papal; por ter formado a Universidade de Nápoles (1224), que hoje leva o seu nome; e por ter incentivado a Escola Siciliana de poesia, de onde tiveram origem as primeiras composições literárias em língua siciliana, e que depois exerceriam influências em autores como Dante e Petrarca. Cf. MILZA, Pierre. Storia d'Italia. Milano: Corbaccio, 2006. p. 247-254.

${ }^{4}$ No original: "La notazione libera e laica, irripetibile e peculiare dell'esperienza salernitana, che poneva la scuola al di fuori del diretto controllo della Chiesa, è forse alla base di questa straordinaria apertura al mondo delle donne, accettate tanto come studentesse che come insegnanti in tutti $i$ campi specilistici, e non solo nell'ostetricia [...]. Questo aspetto è di fondamentale importanza, dal momento che permetteva alle medichesse di riscattarsi dalla condizione sommersa di praticanti empiriche, per esprimersi in una dimensione intellettuale, teorica, fino ad allora controllata dal mondo professionale maschile"
} 
escolhas dos autores ou autoras a serem traduzidos/as? Como traduzir, que tipo de linguagem utilizar, já que a linguagem nunca é neutra? Tais aspectos mereceriam uma discussão à parte; interessa-me, nesse momento, pensar a tradução de Trotula na perspectiva da tradução feminista, ou seja, dentro de uma prática textual voltada a subverter a unilateralidade do discurso patriarcal através de procedimentos transformativos que se configuram como práticas de resistência (GODART, 1990). Se a tradução é um lugar de escolhas políticas, e não apenas de escolhas linguísticas, se a tradução é a ponte através da qual se media duas culturas, dois espaços geográfico-temporais, dar vez à voz das mulheres através da tradução também é um ato crítico de reescrita ${ }^{5}$. Não há tempo aqui para acompanhar a história do tratado de Trotula, mas, em suma, se Trotula foi conhecida na sua época, nos períodos que se seguiram, ela foi relegada aos porões da história, sua existência questionada e suas obras foram atribuídas a homens. Somente no século XX, especificamente em 1930, uma obstetra canadense, chamada Kate Hurd-Mead, escreveu um texto em que defendeu a veracidade da existência de Trotula, chamando, assim, a atenção da comunidade científica e acadêmica sobre o assunto (BARILLARI, 2012). Felizmente, de lá pra cá, vários estudos sobre Trotula surgiram; pelo menos quatro traduções atuais da sua obra: duas edições italianas, uma inglesa e uma brasileira, além de estudos críticos e textos de ficção sobre a autora.

Médica e professora da Escola de Medicina de Salerno, a protagonista da minha explanação é uma mulher que poderia representar os "ausentes" da história, já que, por muito tempo, ela assim esteve, não obstante a importância que teve, seja no seu tempo, seja nos séculos que se seguiram, se considerarmos, por exemplo, registros iconográficos da época, que retratam a sua figura e a difusão das suas obras conhecidas hoje, as quais, ainda no medievo, foram traduzidas para várias línguas, dentre elas o alemão, o holandês e o francês (CAVALLO, 1994, p. 11)

Quando se fala em obras de Trotula, faz-se referência a dois tratados específicos, $D e$ passionibus mulierum ante, in e post partum [Sobre as doenças das mulheres antes, durante e depois do parto] e De ornatu mulierum [Sobre a beleza das mulheres], que teriam circulado inicialmente como um compêndio de práticas médicas específicas para as mulheres com o título de Trota, ou Trocta, diminutivo de Trotula, possivelmente em referência à autora. De fato, a existência de Trotula está envolta em muitos silêncios, e poucas são as informações de que dispomos para conhecer em detalhes a sua trajetória. Tradicionalmente, acredita-se que tenha

\footnotetext{
${ }^{5}$ Refiro-me aqui à tradução do texto de Trotula que realizei em conjunto com Luciana Calado Deplagne e Alder Calado. Cf. RUGGIERO, Trotula di. Sobre as doenças das mulheres. (Tradução e organização: Alder Calado, Karine Simoni e Luciana Calado Deplagne. Florianópolis: UFSC/DLLE/PGET, 2018.
} 
contraído matrimônio com o médico Giovanni Platerio, de cuja união teriam nascido Giovanni e Matteo, também médicos, e, segundo a Storia Ecclesiastica, do cronista inglês e monge beneditino Orderico Vitale, em 1059 um erudito, em passagem por Salerno, teria encontrado uma douta senhora, à qual o nome de Trotula foi relacionado (MADERNA, 2017). Pina Boggio Cavallo (1994), por sua vez, credita à figura de Trotula certidões fúnebres da catedral de Salerno, datadas de 1085 e 1097, prováveis anos de sua morte. Ainda segundo essa pesquisadora, existem mais de cem manuscritos da obra de Trotula, o que corrobora com a hipótese de que tenha realmente existido uma mulher, médica, com esse nome. Tais manuscritos estão guardados em bibliotecas de Bruxelas, Oxford, Leipzig, Cambridge, Londres, Breslávia, Paris, Vindobona, Munique, Florença, Madri e Cidade do Vaticano. E dada a sua natureza, dificilmente poderão nos conduzir a um protótipo do texto de Trotula, pois os diferentes manuscritos, apesar de terem conteúdos homogêneos e muito similares, apresentam, muitas vezes, composição e estrutura distintas entre si; são o testemunho do valor dos ensinamentos neles contidos. Teriam circulado três variantes da obra de Trotula até 1544, ano em que o editor Georg Kraut sistematizou o conteúdo dos três manuscritos, transformando-os em um só e publicando-o pela primeira vez com o uso da prensa, sob o título De passionibus mulierum ante, in et post partum, versão do texto mais difundida até hoje (CAVALLO, 1994, p. 33-36).

Em relação à estrutura da obra, De passionibus mulierum, segundo o trabalho de compilação de Georg Kraut, compreende o tratado sobre as doenças e o tratado sobre a beleza, e está dividido em 61 capítulos, mais dois capítulos que teriam sido inseridos a posteriori. Para fins didáticos, podemos dividi-lo em duas partes: na primeira, que compreende 60 capítulos de extensão variada, cada qual com um assunto, Trotula trata de problemas como a falta ou o excesso das menstruações, o prurido e o inchaço nos órgãos genitais, a infertilidade feminina e masculina, o câncer, o excesso de suor, as hemorroidas, a disenteria, a presença de piolhos e sarnas, a dor de dente, o mau-hálito, as feridas na pele, as doenças dos olhos e da garganta; além disso, apresenta sugestões tanto para evitar a gravidez quanto para alcançá-la, os cuidados durante o período da gravidez, meios para tornar o parto menos dolorido e cuidados com o recém-nascido e com a mulher após o parto, soluções para repor a virgindade da mulher, formas para emagrecer e para acalmar o desejo sexual das mulheres impossibilitadas de realizá-lo. A farmacopeia para cada tratamento concentra-se na natureza das ervas medicinais - no tratado, são citadas cerca de duas centenas de ervas diferentes - divididas entre "quentes" e "frias" e 
ministradas de modo puro ou misturadas entre si, em forma de chás, emplastros, pessários ${ }^{6}$, pomadas, unguentos ou fumigações que tinham, em última instância, o objetivo de promover e ou restituir o bem-estar da paciente, com ensinamentos acessíveis às mulheres de diferentes condições sociais.

Feitas essas breves considerações, proponho a seguir uma possível leitura da obra de Trotula com foco nas suas "lições", tendo como espinha dorsal a defesa da tradução, em especial da tradução feminista ${ }^{7}$, como um dos principais meios para recuperar inúmeras mulheres que, silenciadas pelas práticas e discursos gendrados, mantiveram-se forçosamente "ausentes da história".

É válido lembrar que a luta contra os males físicos - as doenças - ocupou, sem sombra de dúvida, cada período e sociedade histórica, confundindo-se, ou co-fundindo-se, com a história da própria humanidade. Esses males são, muitas vezes, incompreensíveis e indomáveis - nem as fórmulas matemáticas, nem a filosofia, nem a metafísica e/ou qualquer outro tipo de conhecimento conseguiu vencê-los por completo. Para ficarmos nas civilizações mais conhecidas a partir do século XVII d.C., assírios, gregos, egípcios, chineses, todas procuraram explicar a causa dos males e sofrimentos físicos, e também curá-los, dominá-los, preveni-los, e todo o conhecimento que foi sendo adquirido foi também sendo transmitido através da tradução. Seria realmente difícil pensarmos o que teria acontecido se cada civilização tivesse fícado limitada ao conhecimento produzido no seu próprio espaço geográfico, linguístico e cultural; sem os tradutores e tradutoras, não teria havido circulação do conhecimento, não haveria evolução das línguas, do comércio, da ciência, da literatura, da medicina.

Por tal motivo, para falar do que, a partir da minha leitura, entendo como "lições" ou ensinamentos de Trotula aos nossos dias, gostaria de apresentá-la aqui, antes de tudo, como uma tradutora cultural, uma ponte entre o conhecimento antigo que adquirira nos livros disponíveis em seu tempo e a realidade que visualizou de forma mais empírica, para, finalmente, através da escrita, repassar ao futuro aspectos da sua medicina, modo de viver,

\footnotetext{
${ }^{6}$ Espécie de acessório inserido no canal intravaginal para ajudar a dar suporte nos tratamentos ao prolapso dos órgãos pélvicos.

${ }^{7}$ Para aprofundar o assunto, sugiro os seguintes textos: BARBOZA, Beatriz Regina Guimarães; MATOS, Naylane Araújo; SANTOS, Sheila Cristina. Estudos feministas de tradução: um recorte de pesquisas do Programa de Pósgraduação em Estudos da Tradução (PGET-UFSC). In: Belas Infiéis, 7(2), Brasília, 2018; BLUME, Rosvitha Friesen. Teoria e prática tradutória numa perspectiva de gênero. In: Fragmentos, n. 39, Florianópolis, 2010; CASTRO, Olga. (Re)examinando horizontes nos estudos feministas de tradução: em direção a uma terceira onda? Tradução de Beatriz Barboza. TradTerm, São Paulo, v. 29, jul. 2017; DÉPÊCHE, Marie-France. A tradução feminista: teorias e práticas subversivas: Nísia Floresta e a Escola de Tradução Canadense. In: Textos de História. Brasília, v. 8, n. 1, 2000.
} 
filosofia e visão de mundo. Uma tradutora, médica, professora que elaborou a sua própria síntese a partir das práticas ancestrais das parteiras e curandeiras, do estar junto ao leito das pacientes, da leitura de textos de Hipócrates e Galeno, do convívio com seus colegas da Escola de Salerno, como podemos atestar nas linhas do seu tratado. Os cinco pontos ou "lições" que estabeleço aqui foram pensados a partir da experiência de tradução e, naturalmente, não se apresentam como estudo conclusivo ou inalterável; pelo contrário, podem ser questionados, ampliados, melhorados.

Como primeira lição de Trotula, estabeleço a necessidade do (re)conhecimento do corpo feminino que emerge do seu tratado. Proponho iniciar com duas questões, no intuito de fazer um esforço para nos deslocarmos até o período: o que podemos compreender por "conhecer" e "corpo" naquele contexto? Poderíamos, antes de tudo, considerar que a liberdade de explorar o corpo humano, buscando verdades independentes daquelas encontradas em textos clássicos de referência, como os de Hipócrates (460 - 370 a.C.) e Galeno (129 - aproximadamente 217), é uma conquista posterior a Trotula. No século XI, as dissecações humanas ainda eram proibidas pelo contexto cultural-religioso, que via o corpo, ainda que impuro, como algo sagrado e, por isso, inviolável. O ensino médico-cirúrgico dava-se através da leitura dos clássicos, privado da observação direta do cadáver, de modo que, somente em 1376, a faculdade de Montpellier recebeu autorização para dispor do cadáver de um supliciado para fins de estudo, e, antes de 1407, não se tem notícias de dissecação de cadáveres em Paris (POUCHELLE, 2002). Podemos, então, aferir que o conhecimento de Trotula advinha de duas fontes principais: a primeira seria do estudo dos já citados Hipócrates e Galeno, que Trotula, sem dúvida, considerava como referências úteis, como se pode verificar pelas onze menções ao nome "Galeno" e três menções ao nome "Hipócrates" no tratado Sobre as doenças das mulheres. A segunda fonte do conhecimento de Trotula seria proveniente, sobretudo, da observação da paciente, do vigiá-la para perceber os sintomas e intuir as causas, indícios estes que notadamente encontramos ao longo de todo o texto, como no exemplo que segue:

Se, portanto, a mulher não puder engravidar por causa do excesso de calor e aridez do útero, os sinais são estes: os lábios da vulva aparecem ulcerados, como se esfolados pelo vento boreal, com manchas roxas; manifesta-se também uma sede constante e queda de cabelo. Quando notar essas coisas e a mulher tiver trinta anos, pode julgá-la incurável. (RUGGIERO, 2018, p. 69).

Aos olhos da medicina atual, podemos avaliar que propor o melhor tratamento somente depois da observação prolongada dos sintomas era uma maneira muito lenta de se relacionar com a doença; era preciso deixá-la seguir seu rumo a fim de que pudesse manifestar-se em 
diferentes etapas antes de qualquer diagnóstico mais preciso, talvez porque nem mesmo os textos de Hipócrates e Galeno conseguissem proporcionar uma descrição exata de todos os casos. Quero dizer com isso que, embora Trotula certamente não tivesse escrito seu tratado sem o estudo dos seus predecessores, em especial de Galeno, seria igualmente oportuno questionar que Galeno Trotula conhecia. É inegável que as traduções do árabe tiveram um papel fundamental na evolução do saber médico na Europa; em especial, há de se considerar o papel dos tradutores e tradutoras, boa parte deles/as estabelecidos/as em Salerno, pela sua já citada tendência à intensa movimentação de povos árabes e gregos. Figura importante nesse processo foi Constantino, o Africano, que pesquisou e traduziu vários manuscritos médicos do árabe para o latim no mosteiro de Monte Cassino, próximo à Salerno, e permitiu, com isso, o ingresso de novas vertentes do saber médico cristalizado em outras regiões, além do estabelecimento do estudo de Galeno (PORTER, 2008). Porém, embora muitos dos textos de Galeno tenham sido traduzidos para o latim até 1190, somente nos séculos seguintes, em especial nos séculos XIV e XVI, houve uma difusão mais ampla de suas obras (PORTER, 2008). Seria preciso, portanto, um estudo mais detalhado para relacionar os textos de Galeno que Trotula, de fato, conhecia, com as implicações desses textos no tratado Sobre a doença das mulheres. Creio que esse aspecto seria fundamental para identificar com mais segurança qual seria a "novidade", ou "novidades", de Trotula. Arrisco a hipótese de que o mérito de Trotula está em direcionar o conhecimento de Galeno e Hipócrates, ao menos o que ela dispunha na sua época, para a saúde da mulher. Baseio-me, sobretudo, nos estudos histórico-críticos aqui citados, que indicam a possibilidade de as mulheres ingressarem na Escola de Medicina de Salerno, o que poderia ser visto como um indício para a valorização do "ser mulher", e também o próprio registro de Trotula, que, no início do seu tratado, afirma:

\footnotetext{
Porque as mulheres são por natureza mais frágeis que os homens, nelas as doenças abundam com mais frequência, sobretudo em torno dos órgãos reservados à função natural. Como esses estão posicionados em um lugar mais íntimo, por pudor e pela fragilidade da sua condição, elas não ousam revelar ao médico as aflições das suas enfermidades. Por tal motivo, eu, tendo compaixão pela sua desventura e particularmente impulsionada pela solicitação de uma certa senhora, comecei a ocupar-me diligentemente das doenças que muito frequentemente molestam o sexo feminino. (RUGGIERO, 2018, p. 37).
}

De fato, mesmo um olhar panorâmico mostra-nos que boa parte do Sobre as doenças das mulheres é dedicada à diferenciação dos corpos masculino e feminino, o que se daria, sobretudo, pela menstruação. O termo "menstruação" aparece trinta e oito vezes no tratado, e "útero" aparece noventa e quatro. Trotula, ao que parece, e pelos motivos citados anteriormente, 
provavelmente dispunha de certa dose de liberdade para falar, atender e escrever sobre o assunto, despontando, como ela própria deixa entrever, como uma espécie de porta-voz das mulheres que, por pudor e fragilidade, não se sentiam à vontade para revelar ao médico as aflições das suas enfermidades. Temos, então, que as doenças das mulheres estão relacionadas à constituição do seu corpo, em especial à existência do útero, de onde advinham as menstruações. Ainda no prefácio, Trotula retoma o conhecimento de Hipócrates (e talvez de Galeno?) e relaciona as doenças das mulheres com as menstruações muito ou pouco abundantes, ou seja, as doenças do corpo feminino são explicadas pelo desequilíbrio menstrual. Mulheres que têm o fluxo menstrual mais intenso se tornam frágeis, magras; mulheres que têm falta de fluxo ficam pálidas, sem vida (RUGGIERO, 2018).

Fica evidente, para Trotula, que boa parte das doenças das mulheres é ocasionada também pelo movimento do útero. Há, de fato, vários momentos no tratado em que Trotula descreve os deslocamentos desse órgão, em uma alusão bastante evidente ao conhecimento do corpus hipocrático, no qual "os tratados sobre as doenças específicas das mulheres e ligadas à sua função reprodutora ocupam uma parte importante. Muitos traços da sua natureza específica explicam-se pelo papel dado ao útero" (MOSSÉ, 1985, p. 50). Cito alguns exemplos de como Trotula aborda a questão do deslocamento do útero, que se desloca ou para cima, dificultando a respiração e os movimentos cardíacos, ou para o lado e para baixo, e que, inclusive, pode sair do corpo:

Às vezes o útero se comprime, pois se desloca visivelmente em direção ao alto,
causando um distúrbio no estômago e diminuição do apetite por causa do
enfraquecimento do coração. [...] Às vezes o útero se desloca de sua posição, às vezes
desce e outras vezes sai através da vulva. Isso acontece por causa do enfraquecimento
dos nervos e do excesso de humores frios. Na verdade, tal fraqueza e resfriamento
acontecem por causa do ar frio que se introduz pelos orifícios do útero, como quando
a mulher se expõe descoberta diretamente ao ar frio, ou fica muito tempo sentada
sobre uma pedra fria. Às vezes acontece por causa de um banho de água fria; com isso
o útero se debilita e se desloca da sua posição. [...] Depois, tendo o útero saído e tendo
sido tomado na mão, deve ser levado novamente até o lugar de onde se desprendeu.
[...] Existem também mulheres nas quais o útero sai por outras causas; são aquelas
que não podem suportar o membro masculino pelo seu comprimento ou grandeza;
todavia, são obrigadas a aceitá-lo e sofrem, mas o útero depois sai do lugar e endurece.
(RUGGIERO, 2018, p. 53, p. 57-59, p. 113).

Naturalmente, precisamos olhar essas afirmações com os olhos da época, em que não se tinha, como procurei mostrar, dentre outras questões, conhecimento anatômico suficiente para analisar em detalhes o funcionamento interno do corpo humano. O corpo era, portanto, um ser bastante desconhecido, e o conhecimento das suas dinâmicas e estruturas dependia basicamente da aceitação dos saberes já existentes, em especial dos estabelecidos por Hipócrates e Galeno, 
e da observação dos sintomas. Nesse ponto, seria válido talvez compreender as doenças no medievo, em geral, como estratégias de cristianização das consciências, considerando-se que "a Igreja rejeitou como suspeita toda prática curativa não avalizada pela medicina galênica" (POUCHELLE, 2002, p. 155). Não seria absurdo, sob esse ponto de vista, pensar que as suposições de Trotula sobre o deslocamento do útero reproduzissem meramente o que era aceito como verdade na época, talvez como estratégia para que seu tratado fosse, de fato, aceito entre a comunidade médico-científica. Como mulher e como médica, não deve ter sido comum atender pacientes nas quais o útero tenha saído do corpo e recolocado no lugar com a ajuda das mãos, como ela afirma. Estaria Trotula sendo irônica ao reproduzir essas afirmações, já que não poderia, a priori, combatê-las? Como contrariar a autoridade de Hipócrates e Galeno sem prejuízos para a própria imagem? Poderíamos pensar, assim, em uma estratégia de Trotula, certamente presente também em outras autoras mulheres, para questionar o paradigma médico dominante sem afrontá-lo diretamente $?^{8}$

Como segunda "lição" de Trotula, trago a atenção dispensada ao cuidado com o corpo. Só quem conhece, e esse conhecimento, como procurei mostrar, advém da observação dos sintomas, consegue realmente cuidar. Para cada problema, para cada tipo de temperamento, há uma forma de tratamento, e dentre os mais citados estão as fumigações, chás, emplastros, banhos. Trotula, portanto, manifesta vivamente no seu tratado o conhecimento da botânica destinado às mulheres para o alívio dos sintomas, cura e prevenção das doenças. São referenciadas no tratado cerca de 200 ervas diferentes, divididas, por sua vez, em ervas "quentes" e "frias", ministradas de modo puro ou misturadas através da ingestão de chás, infusões, emplastros, pessários, pomadas, unguentos, banhos de vapor e de água. Em todo o tratado, apenas uma vez Trotula recomenda a sangria como tratamento, um método mais agressivo e que envolvia mais riscos para a paciente. Por outro lado, um dos remédios mais recomendados era a fumigação com substâncias de cheiros agradáveis e/ou odores fétidos. Essa diferenciação na escolha do tratamento mais adequado pode ser compreendida a partir da diferenciação que existia entre médico e cirúrgico. Sobre o assunto, escreve Daniele Mont D’Arpizio:

Era uma vez, a medicina, a "nobre arte” de Hipócrates e Galeno: para professá-la, era preciso ser muito filósofo e um pouco astrólogo, conhecer os clássicos latinos e gregos e preparar misturas. Havia também a cirurgia, irmã mais nova e negligenciada, muitas vezes confiada a indivíduos práticos e um tanto ignorantes. Foi assim por séculos, até

\footnotetext{
${ }^{8}$ As reflexões sobre o deslocamento do útero me foram possíveis graças à Ana Miriam Wuensch, do Departamento de Filosofia da Universidade de Brasília, a quem agradeço pela generosidade em compartilhar suas ideias e inquietações.
} 
que as duas disciplinas se aproximaram graças ao trabalho de personalidades como Ruggero di Frugardo, Teodorico di Lucca e Bruno da Longobucco. (D'ARPIZIO, 2019 , p. 19) 9 .

Junto à escolha do melhor tratamento a partir da visão médica, e não cirúrgica, fica bastante evidente em Trotula a preocupação com o nutrimento da paciente. Na concepção de Hipócrates, retomada por Trotula ao longo de todo o tratado, o corpo humano é formado por grupos de oposição: cru versus cozido; calor versus frio; seco versus úmido. Esse entendimento é importante para compreendermos as razões pelas quais determinados tipos de alimentos seriam mais úteis, ou prejudiciais, para cada tipo de febre e outras doenças. Escreve Trotula:

$\mathrm{Na}$ França, um médico fez o seguinte: pegue gengibre, folhas de louro e sabina, esmague-os juntos em uma panela de barro, coloque-os sobre brasas em um banco forrado; a mulher deve sentar-se sobre isso e receber o vapor nas partes inferiores, e assim as menstruações irão voltar; isso deve ser feito três ou quatro vezes ou mais. A mulher que fizer essas fumigações com frequência deve untar a parte interna da vulva com unguentos frios para que não se aqueça muito. [...] Para os fins citados, também é benéfica uma fumigação de cominho, funcho, endro, calaminta, menta, urtiga, misturados ou separados. Também são benéficos a escarificação e, do mesmo modo, o coito. Por outro lado, é maléfica a sangria feita na mão. Se estiver sem febre, a paciente deve comer alho-porró, cebola, pimenta, alho, cominho, peixes escamosos; deve beber também vinho forte se estiver sem dor de cabeça, sem enfraquecimento de nervos e sem febre, porque em todas as febres o vinho faz mal. (RUGGIERO, 2018, p. 47).

Fundamental para o exercício da medicina era considerar que o corpo humano contém sangue, e este, tanto para Hipócrates como para Trotula, é composto por humor viscoso, bílis amarela e bílis negra. A saúde é, em primeiro lugar, o estado em que essas substâncias se encontram em proporção correta uma em relação à outra. A doença aparece quando há falta ou excesso de uma dessas substâncias, ou quando elas não estão adequadamente misturadas (MOSSÉ, 1985). A doença é, pois, um desequilíbrio, resultado de fatores externos, ligados ao clima, ou a fatores internos, como a alimentação, e a ação do/a médico/a é indicar aos que gozam da saúde o meio de manter esse equilíbrio dos "humores" do corpo, e, por outro, tentar restabelecê-lo quando esse estado de bem-estar desaparece. No caso de Trotula, vemos continuamente que a base da saúde era a busca do equilíbrio defendido por Hipócrates, e tal equilíbrio viria também pela limpeza do corpo. É por isso que notamos, praticamente em todo tratamento, o papel que a limpeza do corpo possui para Trotula. Quanto mais purificado o corpo,

\footnotetext{
${ }^{9}$ No original, "C'era una volta la medicina, la "nobile arte" di Ippocrate e di Galeno: per professarla bisognava essere molto filosofi e un poco astrologi, conoscere i classici latini e greci e saper preparare intrugli. C'era poi la chirurgia, sorella minore e negletta, spesso affidata a individui praticoni e un po' ignoranti. Fu cosi per secoli, fino a quando le due discipline si riavvicinarono grazie all'opera di personalità come Ruggero di Frugardo, Teodorico di Lucca e Bruno da Longobucco."
} 
mais próximo à saúde, por isso a ideia de provocar o suor, a escarificação e a urina; incentivar a ingestão de líquidos, os banhos de água e de vapor.

Em sequência, proponho como terceira lição de Trotula a disposição em ajudar e sobre a autoridade do/a médico/a, cujas referências são encontradas no próprio Sobre as doenças das mulheres. Embora raras sejam as informações sobre a vida da autora, há uma passagem em que se narra a experiência da médica com uma jovem, depois do parto, que sofria desenganada. Trotula, então, a levou para a sua casa e narra o motivo:

[...] para conhecer de modo privado a causa de sua enfermidade e, tendo notado que a dor não dependia da ruptura ou do inchaço do útero, mas da flatulência, fez com que preparassem para ela um banho em que foram colocadas para cozinhar malva e parietária, introduziu-as nela, e tratou repetidamente e com delicadeza as partes acometidas, amaciando-as. (RUGGIERO, 2018, p. 99).

Outro momento em que é visível a ligação entre o cuidado com o corpo e o cuidado com aspectos emocionais da paciente - o que implica em cuidá-la e, da mesma maneira, cuidar do ambiente que a rodeia, de modo a favorecer, antes de tudo, o bem-estar emocional da paciente, preservando-a o máximo possível nos momentos em que está mais necessitada de auxílio e de solidariedade - está no seguinte caso:

Em primeiro lugar, então, se a dificuldade no parto for observada, é preciso principalmente recorrer a Deus. Passando aos auxílios terrenos, é bom para a mulher que tem dificuldade de dar à luz banhar-se na água onde foram cozidas malva, feno grego, semente de linho e cevada. Devem ser untados os quadris, o abdômen, as coxas e a virilha com óleo violáceo ou de rosas; ela deve ser massageada com força e lhe devem ser oferecidos oxyzaccara ${ }^{10}$ e uma dracma de menta em pó e absinto. Devem ser provocados espirros com pó de incenso introduzido nas narinas, ou com pó de candiso $^{11}$, de pimenta ou de eufórbia. A mulher deve ser conduzida pela casa com passos lentos e aqueles que cuidam dela não devem olhar em seu rosto, porque as mulheres a esse olhar costumam envergonhar-se durante e depois do parto. (RUGGIERO, 2018, p. 83).

Como quarta lição, subentendo a prática "racional" da medicina, que poderia assinalar uma espécie de divisão entre as práticas médicas vivenciadas por Trotula e as acepções mais corriqueiramente encontradas na medicina dita "popular", aquela das medichesse. Dito de outro modo, há em Trotula um visível afastamento das práticas “mágicas”, explicadas por um poder sobrenatural onisciente e onipresente, que, às vezes, tinha vestes das divindades, outras vezes, de seres trevosos. Trotula busca uma medicina mais racional: desvendar as causas dos fenômenos, compreender o funcionamento do corpo a partir do conhecimento já existente e da

\footnotetext{
${ }^{10}$ Espécie de xarope que resulta da fervura de açúcar e vinagre, utilizado para combater a febre e a bílis do estômago. [ N.T.]

${ }^{11}$ Açúcar purificado e cristalizado. [ N.T.]
} 
observação empírica da realidade, e, a partir daí, elaborar e prescrever os remédios e tratamentos apropriados. $\mathrm{O}$ voltar as costas às explicações sobrenaturais não significava negar a eficácia de certas possibilidades de cura, mas sim, denotava a tentativa de fazer da medicina uma ciência - por isso também era ensinada em uma Escola - e uma prática mais racional, dada, repito, sobretudo por nomes como Hipócrates e Galeno, que haviam sido pioneiros em aplicar as regras do pensamento filosófico-racional às práticas médicas. Não quer dizer que não exista no tratado referências mágicas, que não passam de três ou quatro, como a que mostro aqui:

\begin{abstract}
Existe uma pedra, chamada azeviche, que levada junto ao peito ou mesmo consumida é um obstáculo para a concepção. De modo similar, pegue um macho de fuinha, remova os seus testículos e deixe-o vivo; esses testículos a mulher deve carregar consigo no seu peito fechados dentro de uma pele de pato ou outra pele, e não engravidará. [...] Deve-se notar que existem alguns remédios naturais, cuja energia é desconhecida para nós, que são úteis quando aplicados pelas obstetras. A paciente, portanto, deve segurar um ímã na mão direita, que lhe fará bem. Da mesma forma, deve beber raspas de marfim. Também pode utilizar um coral pendurado ao redor do pescoço. De modo semelhante, é reconfortante beber a famosa substância branca encontrada nas fezes de aves de rapina. Igualmente, na barriga da andorinha ou no ninho está a pedra do primogênito, a água que resta de sua lavagem é benéfica para a mesma coisa e para muitas outras. (RUGGIERO, 2018, p. 81, p. 75).
\end{abstract}

Vemos, portanto, em Trotula, diferentes camadas de conhecimento e de pensamento, que, não necessariamente, precisam ser vistos como opostos. Notamos junto ao estudo dos autores consagrados da medicina também crenças e práticas da medicina mais popular, em que o corpo feminino é visto como uma imagem positiva, um corpo com paixões, pulsões; um corpo que deve e merece ser bem cuidado e ficar bonito, o que seria contestado, como sabemos, nos séculos posteriores, de modo mais evidente nos séculos da Inquisição.

Para finalizar, poderia ser identificada como quinta lição o fato de Trotula mostrar preocupação com o alcance da saúde e sua democratização. Prova disto está no fato de a autora prescrever receitas com ingredientes para ricos e para pobres ao afirmar: "Pegue resíduo de prata, de cobre, de ferro, de chumbo, de aço, de ouro, litargírio de prata e de ouro, de estoraque, de acordo com a condição rica ou pobre do paciente" (RUGGIERO, 2018, p. 171). Ainda,

\footnotetext{
[a] paciente deve resguardar-se especialmente do frio; não deve ser feita sufumigação de substâncias aromáticas nas narinas dela, mas esse tratamento pode ser executado com mais tranquilidade no orifício do útero, uma vez que ele responde bem a substâncias aromáticas e foge daquelas fétidas. Para esse fim são benéficas substâncias odoríferas como almíscar, âmbar, madeira de ágar e semelhantes para as mulheres ricas; ervas aromáticas como menta, poejo, calaminta, orégano e similares para as pobres. (RUGGIERO, 2018, p. 81).
}

A leitora e o leitor de Trotula certamente encontrarão numerosa quantidade de exemplos e também de "lições" outras de Trotula, com as quais podemos, ainda hoje, estabelecer diálogos 
que servem para a ressignificação dos nossos conhecimentos. "O sujeito ocidental é o resultado de um intenso trabalho do corpo" (CORBIN; COURTINE; VIGARELLO, 2012, p. 13), da construção desse corpo. Seria preciso esperar pelo século XIX, com avanços até então nunca vistos na história da medicina, para que o/a médico/a adquirisse um conhecimento mais preciso do corpo humano. Não podemos esquecer que o que nos parece natural hoje, como a higiene e a boa alimentação, foi sendo lentamente construído, elaborado, manipulado, incorporado. $\mathrm{O}$ tratado de Trotula é, nesse sentido, um documento que conta uma possível história da medicina e das mulheres no medievo, e tem como uma das principais contribuições tornar mais possível a visibilidade da mulher, fazer-nos refletir sobre o lugar e o papel da mulher nas sociedades do passado, do presente e do futuro. É evidente que, em nosso tempo e depois de termos passado por lutas feministas que ainda não se esgotaram, interessa saber como pensavam e o que escreviam as mulheres dos séculos anteriores, como elas viam o seu papel, o papel das mulheres de seu tempo. Nesse sentido, retomo a ideia da tradução como instrumento político, histórico, capaz de promover a tomada de consciência das coibições que operam no processo de escrita e reescrita dos textos, capaz de olhar criticamente para os poderes e manipulações várias que interferem na história do livro e das mulheres e, por fim, igualmente capaz de criar novas formas de expressão e de reflexão do/ sobre e para o mundo.

\section{Referências}

BARBOZA, Beatriz Regina Guimarães; MATOS, Naylane Araújo; SANTOS, Sheila Cristina. Estudos feministas de tradução: um recorte de pesquisas do Programa de Pósgraduação em Estudos da Tradução (PGET-UFSC). In: Belas Infiéis, 7(2), Brasília, 2018.

BARILLARI, Sonia. Il corpo delle donne: il magistero di Trocta. In: CASARETTO, Francesco Mosetti. Il corpo impuro e le sue rappresentazioni nelle letterature medievali. Alessandria: Edizioni dell’Orso, 2012.

BLUME, Rosvitha Friesen. Teoria e prática tradutória numa perspectiva de gênero. Fragmentos, n. 39, Florianópolis, 2010.

CASTRO, Olga. (Re)examinando horizontes nos estudos feministas de tradução: em direção a uma terceira onda? Tradução de Beatriz Barboza. TradTerm, São Paulo, v. 29, jul. 2017.

CAVALLO, Pina Boggi. Introduzione. In: RUGGIERO, Trotula. Sulle malattie delle donne. Trad. Piero Cantalupa. Palermo: La Launa, 1994.

COURBIN, Alain; COURTINE, Jean-Jacques; VIGARELLO, Georges. (orgs.) História do

Corpo. Vol. I. Tradução de Ephraim Ferreira Alves. Petrópolis: Vozes, 2012. 
D'ARPIZIO, Daniele Mont. Dai Barbieri ai chirurghi: il "bisturi" cambia di mano. In: REDAZIONE DEL BO LIVE. Medici rivoluzionari. La scienza medica a Padova dal Duecento alla Grande Guerra. Padova: University Press, 2019. p. 19-23.

DÉPÊCHE, Marie-France. A tradução feminista: teorias e práticas subversivas: Nísia Floresta e a Escola de Tradução Canadense. Textos de História. Brasília, v. 8, n. 1, 2000.

FLOTOW, Luise von. Translation and Gender. Translation in the era of Feminism. Manchester, St. Jerome Publishing; Ottawa, University of Ottawa Press, 1997.

GODARD, Barbara. Theorizing feminist discourse/translation. In: LEFEVERE, André; BASSNETT, Susan (org.). Translation, history and culture. New York: Pinter Publishers Limited, 1990. p. 87-96.

LINKIESTA. Quesiti linguistici. La Crusca: si può dire anche "medica" e "medichessa". In: https://www.linkiesta.it/2017/02/la-crusca-si-puo-dire-anche-medica-e-medichessa/. Acesso em 24 mai. 2020.

MADERNA, Erika. Medichesse. La vocazione femminile alla cura. $3^{\text {a }}$ ed. Sansepolcro: Aboca Museum, 2017.

MILZA, Pierre. Storia d'Italia. Milano: Corbaccio, 2006.

MOSSÉ, Claude. As lições de Hipócrates. In: LE GOFF, Jacques. (org.) As doenças têm história. Lisboa: Terramar, 1985. p. 39-55.

PORTER, Roy. Cambridge. História da medicina. Tradução Geraldo Magela Gomes da Cruz e Sinara Mônica de Oliveira Leite. Rio de Janeiro: Revinter, 2008.

POUCHELLE, Marie-Christine. Medicina. Tradução Mário Jorge da Motta Bastos. In. LE GOFF, Jacques, SCHMITT, Jean-Claude. (orgs.) Dicionário Temático do Ocidente Medieval Vol. II. Bauru, SP: Edusc, 2002. p. 151-165.

RUGGIERO, Trotula di. Sobre as doenças das mulheres. (Tradução e organização: Alder Calado, Karine Simoni e Luciana Calado Deplagne. Florianópolis: UFSC/DLLE/PGET, 2018.

TYMOCZKO, Maria, GENTZLER, Edwin. Translation and Power. Amherst/Boston: University of Massachusetts Press, 2002.

VENUTI, Lawrence. A invisibilidade do tradutor. [1986] In: Palavra 3. Trad. Carolina Alfaro. Rio de Janeiro, 1995, p. 111-134.

VENUTI, Lawrence. Escândalos da tradução: por uma ética da diferença. Trad. de Laureano Pelegrin et al. Bauru: EDUSC, 2002.

Recebido em: 15/07/2020

Aceito para publicação em: 19/09/2020 